\title{
A INCLUSÃO DA EDUCAÇÃO AMBIENTAL NOS CONTEÚDOS CURRICULARES DO ENSINO SUPERIOR SUL-MATO- GROSSENSE: CENÁRIOS E PERSPECTIVAS
}

Djanires Lageano Neto de Jesus ${ }^{1}$

Roberta de Arruda Braga Silva²

Resumo: A Educação Ambiental de modo geral trata de assuntos que visa construir uma cidadania voltada a pensamentos sustentáveis. O objetivo deste estudo é de analisar se os cursos superiores de Arquitetura \& Urbanismo, de Geografia e de Turismo ofertados nas Instituições de Ensino Superior (IES) de Mato Grosso do Sul estão contemplando em seus currículos a Educação Ambiental de modo transversal, contínuo e permanente. A metodologia foi baseada no método indireto buscando referenciais teóricos sobre o tema bem como a documentação disponível no site do Ministério da Educação e nos sites das IES do estado de Mato Grosso do Sul. Os resultados parciais apontam pouca transversalidade nos conteúdos sobre questões ambientais abordados pelos cursos superiores analisados no Estado, o que pode oportunizar uma visão restrita dos futuros egressos quando estiverem demonstrando suas competências e habilidades profissionais.

Palavras-chave: Educação Ambiental; Ensino Superior; Transversalidade.

Universidade Estadual de Mato Grosso do Sul Campo Grande, MS. E-mail: netoms@uems.br

2 Universidade Federal de Mato Grosso do Sul, Campo Grande, MS. E-mail: robertadearrudabraga@gmail.com

Revbea, São Paulo, V.11, № 2: 164-177, 2016. 


\section{Introdução}

O ponto de partida para desenvolvimento do presente artigo é o confronto do campo epistemológico com as práticas da inserção da Educação Ambiental não somente na educação infantil e fundamental, mas, sobretudo, no ensino superior, onde se acredita que o processo de consolidação do tema torna-se mais eficaz já que a formação do indivíduo torna-se mais madura. Entretanto, para avaliar sua eficácia sobre as práticas adotadas, um questionamento torna-se importante: De que modo a Educação Ambiental pode estar inserida às disciplinas dos cursos de Geografia, de Arquitetura \& Urbanismo e de Turismo de modo transversal, contínuo e permanente?

Considerando essa indagação o presente artigo tem como objetivo apresentar uma análise de como a Educação Ambiental pode estar inserido às disciplinas dos cursos superiores de modo transversal, contínuo e permanente. Entende-se essa relação de transversalidade, buscando a etimologia da palavra, ou seja, algo que atravessa algo tendo alguma coisa como referente, não obrigatoriamente, na oblíqua. Ou seja, sua eficiência se dará com a confluência de outros sentidos, de modo contínuo e permanente, assim, de forma pragmática, envolvendo conteúdos aplicados das mais variadas áreas de conhecimento entre elas, humanas, sociais, exatas e biológicas.

Nesse sentido, dentre os objetivos específicos verificou-se junto as Diretrizes Curriculares Nacionais de que forma a Educação Ambiental está inserida nos conteúdos programáticos. Além disso, foi identificada a relação do ensino superior com a política de Educação Ambiental para que posteriormente pudesse apontar sugestões sobre práticas de gestão ambiental para serem aplicadas no ensino superior.

Um dos motivos que levaram o desenvolvimento desta pesquisa se deve ao fato de demonstrar a necessidade de confronto da legislação imposta nesse assunto com a efetividade das práticas adotadas pelas IES de forma transversal, pois o que percebe empiricamente é a existência de uma pseudoideologia sobre a necessidade de conservação do meio ambiente, porém ao confrontar com a gestão aplicada pouco se percebe de evolução já que a grande maioria das vezes recai ao senso comum.

Seguindo a recomendação da Proposta de Diretrizes Curriculares Nacionais (DCNs) para a Educação Ambiental sugerida pelo Ministério da Educação por meio da Secretaria de Educação Continuada, Alfabetização e Diversidade Diretoria de Educação Integral, Direitos Humanos e Cidadania Coordenação-Geral de Educação Ambiental, os princípios e objetivos da Educação Ambiental corroboram com os princípios gerais da Educação contidos na Lei 9.394, de 20/12/1996 (LDB - Lei de Diretrizes e Bases).

Dentre as recomendações sobre a práxis pedagógica, a Educação Ambiental envolve o entendimento de uma educação cidadã, responsável, crítica, participativa, onde cada indivíduo aprende com conhecimentos científicos e com o reconhecimento dos saberes tradicionais, possibilitando a tomada de decisões transformadoras a partir do ambiente natural ou construída

revista brasileira educação ambiental 
no qual as pessoas se inserem. As relações, portanto, são construídas por meio do convívio social, nesses contidos a diversidade de gênero, racial, religioso, étnico, sexual e social.

A Educação Ambiental, portanto, tenta avançar na construção de uma cidadania mais equilibrada, estimulando interações mais justas entre os seres humanos e os demais seres que habitam o mundo, na construção de um ideário onde o presente e futuro se fundem na visão sustentável, sadia e socialmente justa.

Apesar de representar uma conquista histórica à menção à Educação Ambiental nas diversas legislações educacionais, especialmente na LDB, no Plano Nacional de Educação (PNE) e em diversas Diretrizes Curriculares da Educação Básica e Superior, nota-se que estas normas ainda não contemplam a inclusão da Educação Ambiental em todos os níveis de ensino e em todas as modalidades, sem 0 destaque das diretrizes contidas na Lei $n^{\circ}$ 9.795, de 27.04.99, que estabelece a Política Nacional de Educação Ambiental (PNEA) diretrizes consideradas obrigatórias para os sistemas pedagógicos formais e não formais.

As legislações educacionais (tais como decretos, resoluções e portarias) ainda não explicam como se dará, na prática, a abordagem desta temática nos estabelecimentos de ensino, nem prescrevem os princípios, diretrizes operacionais e pedagógicas para o seu trato transversal nos níveis e modalidades da educação. Nesse sentido, para desenvolvimento deste trabalho, optou-se pela pesquisa indireta utilizando o método bibliográfico e documental baseando nos referenciais teóricos de referência assim como nos documentos institucionais do Ministério da Educação e do Instituto Nacional de Estudos e Pesquisas Educacionais Anísio Teixeira (Inep), além de uma pesquisa nos sites das IES que ofertam os cursos superiores de Turismo, de Arquitetura \& Urbanismo e de Geografia.

Acredita-se que com a pesquisa que originou o presente artigo, contribuirá na necessidade mudança de comportamento pessoal e profissional lançando mão de buscar práticas para serem inseridas no dia a dia em sala de aula para que as mesmas sejam multiplicadas por meio dos estudantes nas mais diversas áreas de formação superior, já que o tema deve ser tratado com atenção e responsabilidade social.

\section{A Educação Ambiental no ensino superior}

Desde seus primórdios, a humanidade aproveitou a natureza de forma dominadora, acreditando que está nunca seria abalada pelas suas transformações. Porém, os resultados dessa perspectiva geraram consequências desastrosas ao meio ambiente, afetando inclusive o homem. A crise ambiental, no qual hoje se encontra, está relacionada ao manejo exaustivo e incorreto para com a natureza que trouxe resultados alarmantes nos dias atuais. 
A questão ambiental é dos temas mais discutidos da atualidade, onde envolve toda a problemática ambiental, em relação às condições socioambientais de áreas urbanizadas ou não, incluindo os aspectos relacionados à qualidade de vida humana, os impactos da ação humana sobre as condições climáticas, hidrológicas, geomorfológicas, pedagógicas e biogeográficas, em todas as escalas de tempo e espaço (CHRISTOFOLETTI 1993, SOBRAL; SILVA1989).

A humanidade necessita rever novos rumos e refletir sobre outros valores que possam amenizar essas ações provocadas contra o meio ambiente. A introdução sobre assuntos relacionados à questão ambiental na educação é um recente caminho encontrado que visa mudança comportamental do cotidiano para um comportamento sustentável. A Educação Ambiental contribui com uma visão mais considerável que possibilita um relacionamento entre homem e natureza.

Pela Lei 9.795 sancionada no dia 27 de abril de 1999 que dispõe sobre a Educação Ambiental (EA), formando a Política Nacional de Educação Ambiental (PNEA), em seu art. 1을 declara que com a EA, os processos por meio dos quais o indivíduo e a coletividade constroem valores sociais, conhecimentos, habilidades, atitudes e competências são voltadas para a conservação do meio ambiente, bem de uso comum do povo, essencial à sadia qualidade de vida e sua sustentabilidade. Portanto, a EA é o elemento essencial e existente para a educação nacional, onde deve estar presente em todos os níveis e modalidades educativas, de maneira formal e informal, como diz 0 art. $2^{\circ}$.

\begin{abstract}
A Educação Ambiental tem assumido cada vez mais uma função transformadora, na qual a corresponsabilização dos indivíduos torna-se um objetivo essencial para promover um novo modelo de desenvolvimento, chamado por muitos de desenvolvimento sustentável. Entende-se, portanto, que a Educação Ambiental constitui uma das condições necessárias para modificar 0 quadro de crescente degradação socioambiental, com ênfase em um modelo educacional que vise equacionar o relacionamento entre homem e natureza. Dessa forma, a inserção da Educação Ambiental no ensino formal e informal representa uma possibilidade de orientar as pessoas em um caminho que venha a transformar os paradigmas atualmente vigentes, influenciados diretamente na qualidade de vida e cidadania (ZUQUIM; FONSECA; CORGOZINHO, 2010).
\end{abstract}

$\mathrm{Na}$ escola, a Educação Ambiental tem o papel de constituir ações educativas que auxiliam para formação de cidadãos conscientes da importância sobre a preservação do meio ambiente. A inclusão da $E A$ se deu através de elaboração de projetos, que ajuda o processo de aprendizagem e

revista brasileira educação ambiental 
sugere a necessidade de estratégias de ensino mais adequadas além de tornar evidente a importância de um currículo integrado que valorize o conhecimento mais ecológico. Já nas universidades a Educação Ambiental deve ser incluída nos currículos de diferentes cursos estudantes, não como disciplina específica, e sim de uma forma transversal, com uma visão mais ampla sobre questões ambientais e compartilhamento de ideias que visam diminuir impactos causados sobre o meio.

Fonte de construção do saber, a universidade exerce a função mediadora entre espaços de produção e aplicação do conhecimento, articulando-os mediante o desenvolvimento de habilidades, instrumentos e técnicas operatórias, em uma realidade constituída de diferentes grupos e atores sociais; questões culturais e éticas permeiam a totalidade das relações homem-mundo, afetando a forma de satisfazer a necessidade em diferentes espaços de vida (PILON, 2005 p. 312).

No ano de 1977 em Tbilisi aconteceu a Conferência Intergovernamental sobre a Educação Ambiental, em sua recomendação $n \stackrel{0}{13^{\circ}}$, considera que as universidades - na sua qualidade de centro de pesquisa, de ensino e de pessoal qualificado no país - devem dar, cada vez mais, ênfase à pesquisa sobre educação formal e não formal, considera também que a Educação Ambiental nas escolas superiores diferirá cada vez mais da educação tradicional, e se transmitirão aos estudantes os conhecimentos básicos essenciais para que suas futuras atividades profissionais redundem em benefícios para o meio ambiente, a conferência recomenda:

- Que se examine o potencial atual das universidades para o desenvolvimento de pesquisa;

- Que se estimule a aplicação de um tratamento interdisciplinar ao problema fundamental da correlação entre o homem e a natureza, em qualquer que seja a disciplina;

- Que se elaborem diversos meios auxiliares e manuais sobre os fundamentos teóricos da proteção ambiental.

As Instituições Universitárias obtêm de um espaço que compõem diferentes áreas, com isso ela pode prover na formação de profissionais capacitados e habilitados em áreas ambientais de forma transversal. A transversalidade ajuda o estudante há obter uma visão ordenada de um efeito maior para solucionar questões ambientais.

Recorrendo ao que preconiza as grandes áreas de conhecimento científico, a Constituição Federal, ao tratar, em seu Artigo 218, da Ciência e Tecnologia, refere-se a áreas de ciência. Nesse sentido, as agências públicas como o CNPQ e CAPES no Brasil e a comunidade científica, aplica a Revbea, São Paulo, V.11, № 2: 164-177, 2016. 
expressão áreas do conhecimento como instrumento para propagar a arte, ciência, tecnologia, cultura e inovação além de organizar e proporcionar às Instituições de ensino, pesquisa e inovação uma maneira funcional de sistematizar e prestar informações concernentes a projetos de pesquisa e recursos humanos aos órgãos gestores da área de ciência e tecnologia.

A organização das Áreas do Conhecimento na tabela apresenta uma hierarquização em quatro níveis, do mais geral ao mais específico, abrangendo nove grandes áreas nas quais se distribuem as 48 áreas de avaliação da CAPES. Estas áreas de avaliação, por sua vez, agrupam áreas básicas (ou áreas do conhecimento), subdivididas em subáreas e especialidades, como apontada pela CAPES (2014):

10 nível - Grande Área: aglomeração de diversas áreas do conhecimento, em virtude da afinidade de seus objetos, métodos cognitivos e recursos instrumentais refletindo contextos sociopolíticos específicos;

2o nível - Área do Conhecimento (Área Básica): conjunto de conhecimentos inter-relacionados, coletivamente construído, reunido segundo a natureza do objeto de investigação com finalidades de ensino, pesquisa e aplicações práticas;

3o nível - Subárea: segmentação da área do conhecimento (ou área básica) estabelecida em função do objeto de estudo e de procedimentos metodológicos reconhecidos e amplamente utilizados;

4ํ nível - Especialidade: caracterização temática da atividade de pesquisa e ensino. Uma mesma especialidade pode ser enquadrada em diferentes grandes áreas, áreas básicas e subáreas.

Observando esses critérios e condicionando na prática da Educação Ambiental no ensino superior, serão apresentados alguns exemplos de práticas dentro da grande área de Ciências Exatas e da Terra e de Ciências Sociais Aplicadas, mais precisamente na Geografia e na Arquitetura e Urbanismo e também dos cursos superiores em Turismo.

A Geografia é a ciência que estuda as relações entre a sociedade e a natureza, de caráter físico, biológico, econômico, social, cultural e ambiental onde visa compreender e criar novos espaços geográficos. A prática ambiental na Geografia é formada através de estudos relacionados com a natureza, o estudo interdisciplinar do meio ambiente necessita compreender essas relações para que possa haver um controle causado pelos impactos humanos.

A profissão de Geógrafo, regulamentada pela Lei ํo 6.664 de julho de 1979, habilita esse profissional para o levantamento, estudos e pesquisas de caráter físico-geográfico, biogeográfico, antropogeográfico, demográfico, sociocultural, político-econômico e geoeconômico. Permite a elaboração de 
estudos socioambientais tais como EIA (Estudo de Impacto Ambiental) e RIMA (Relatório de Impacto de Meio Ambiente), Planos Diretores, Zoneamentos Ambientais e mapeamentos dos mais diversos tipos.

Analisando a Resolução CNE/CES 14, de 13 de março de 2002, que estabelece as Diretrizes Curriculares para os cursos de Geografia, a mesma não explicita as questões ambientais, diferentemente do próprio conceito das ciências geográficas.

Sendo uma área de conhecimento comprometida em tornar o mundo comprometido em um mundo compreensível para os estudantes e estudantes, a Geografia assume grande relevância dentro dos contextos dos Planos Curriculares Nacionais (PCNs), em sua meta de buscar um ensino para a conquista da cidadania brasileira (PCN, 1998).

A transversalidade são temas propostos para a busca de interdisciplinaridade, onde introduz assuntos atuais relacionados entre a Geografia e a Educação Ambiental. Como ressalta (GARCIA, 2004,) como os temas transversais não constituem uma disciplina, seus objetivos e conteúdos devem estar inseridos em diferentes momentos de cada uma das disciplinas. Vão sendo trabalhados em uma e em outra, de diferentes modos. Interdisciplinaridade e transversalidade alimentam-se mutuamente, pois para trabalhar temas transversais adequadamente não se pode ter uma perspectiva disciplinar rígida.

Assim vale também para a área de Arquitetura \& Urbanismo, que segundo 0 relatório das Diretrizes Curriculares Nacionais (DCNs) desenvolvidas pelo MEC, relata que esta deverá estabelecer ações com base no desenvolvimento de condutas e atitudes com responsabilidade técnica e social, tendo como princípios:

a) a qualidade de vida dos habitantes dos assentamentos humanos e a qualidade material do ambiente construído e sua durabilidade;

b) o uso da tecnologia em respeito às necessidades sociais, culturais, estéticas e econômicas das comunidades;

c) o equilíbrio ecológico e o desenvolvimento sustentável do ambiente natural e construído;

d) a valorização e preservação da arquitetura, do urbanismo e da paisagem como patrimônio e responsabilidade coletiva.

Para (BRÜGGER, 1999), é necessário provocar a quebra de paradigmas e vislumbrar novos caminhos, considerando os ensinamentos direcionados ao uso racional dos recursos naturais à conservação de um índice de produtividade dos ecossistemas naturais ou aqueles administrados pelo homem.

A transversalidade da Educação Ambiental na área de arquitetura condiciona o estudante a explorar, através de suas ideias, a criação de projetos Revbea, São Paulo, V.11, № 2: 164-177, 2016. 
que integram a paisagem urbana com a natural, isto é, a transdiciplinaridade entre a $E A$ e a Arquitetura tem o intuito de gerar novas técnicas sustentáveis, assim quando se tornar arquiteto, leve consigo um diferencial que possibilite promover os conceitos sustentáveis através de seus projetos desenvolvidos através das práticas de Educação Ambiental na universidade.

$\mathrm{Na}$ relação da Educação Ambiental com o campo do Turismo, a Resolução n. 13, de 24 de novembro de 2006 que trata da Institui as Diretrizes Curriculares Nacionais do Curso de Graduação em Turismo, apresenta em seu Artigo $2^{\circ}$, $\S 2^{\circ}$ :

O Projeto Pedagógico do curso de graduação em Turismo poderá admitir Linhas de Formação Específicas, direcionadas para diferentes áreas ocupacionais relacionadas com o turismo, abrangendo os segmentos ecológicos e ambientais, econômicos, culturais, de lazer, de intercâmbio de negócios e promoção de eventos e serviços, para melhor atender as necessidades do perfil profissiográfico que o mercado ou a região exigirem (grifo nosso).

Há de se considerar vários elementos que compõem a atratividade turística, entretanto, o interesse ecológico e ambiental ganha lugar de destaque no cenário nacional, sobretudo, no estado de Mato Grosso do Sul, onde destinos como Corumbá, Bonito e Jardim localizados no Pantanal e na Serra da Bodoquena (locais com rica biodiversidade ambiental), apoiam-se nesse apelo para oferecer pacotes turísticos a demandas diversas. Nesse contexto, a relação do turismo se aproxima não somente nas questões ambientais, como também nas questões estéticas e patrimoniais como permeada na arquitetura e no estudo das relações territoriais advindas da geografia. O estudante de Turismo que percebe essa relação direta entre as áreas de conhecimento, reforça a importância de valorizar a Educação Ambiental como atratividade e manutenção dos recursos para as gerações presentes e futuras.

\section{A disciplina "Educação Ambiental" em Mato Grosso do Sul}

Analisando o cenário do ensino superior no estado de Mato Grosso do Sul, em 2014, mais especificamente nos cursos de Geografia, Arquitetura \& Urbanismo e de Turismo, que possuem em suas matrizes curriculares e nas ementas os conteúdos relacionados à Educação Ambiental, destaca-se o seguinte cenário (Quadro 1): 
Quadro 1: Disciplinas ambientais nos cursos superiores.

\begin{tabular}{|c|c|c|c|}
\hline IES & CURSO & $\begin{array}{l}\text { CONTEMPLA A } \\
\text { EA NA MATRIZ } \\
\text { CURRICULAR }^{\star \star}\end{array}$ & DISCIPLINAS CORRELATAS \\
\hline \multirow[t]{3}{*}{ UFMS } & $\begin{array}{l}\text { Geografia } \\
\text { (Aquidauana, Campo } \\
\text { Grande, Corumbá, } \\
\text { Três Lagoas) }\end{array}$ & $\begin{array}{l}\text { ( x )Sim } \\
\text { ( ) Não }\end{array}$ & $\begin{array}{l}\text { DISCIPLINAS OBRIGATÓRIAS } \\
\text { Planejamento e Gestão Ambiental } \\
\text { Gerenciamento de Resíduos Sólidos } \\
\text { Gerenciamento de Recursos Hídricos } \\
\text { Educação Ambiental } \\
\text { Legislação Urbana e Ambiental } \\
\text { Ecologia Geral } \\
\text { Saneamento Básico e Ambiental } \\
\text { Hidrologia Ambiental }\end{array}$ \\
\hline & $\begin{array}{l}\text { Turismo } \\
\text { (Bonito, Campo } \\
\text { Grande e } \\
\text { Aquidauana) }\end{array}$ & $\begin{array}{ll}\text { ( x ) Sim* } & \\
\text { ( ) Não } & \\
\text { * Apenas na } \\
\text { Unidade } & \text { de } \\
\text { Aquidauana } & \end{array}$ & $\begin{array}{l}\text { DISCIPLINAS OBRIGATÓRIAS } \\
\text { Turismo em áreas naturais } \\
\text { Planejamento e organização do turismo } \\
\text { DISCIPLINAS OPTATIVAS } \\
\text { Avaliação de impactos ambientais } \\
\text { Turismo rural } \\
\text { Ecologia geral } \\
\text { Ecologia do cerrado } \\
\text { Ecologia do pantanal } \\
\text { Ciências do ambiente } \\
\text { Educação Ambiental } \\
\text { Planejamento e gestão ambiental } \\
\text { Percepção ambiental } \\
\text { Turismo e unidades de conservação } \\
\text { Turismo e meio ambiente }\end{array}$ \\
\hline & $\begin{array}{l}\text { Arquitetura* } \\
\text { (Campo Grande) }\end{array}$ & $\begin{array}{l}\text { ( ) Sim } \\
\text { (x) Não }\end{array}$ & $\begin{array}{l}\text { DISCIPLINAS OBRIGATÓRIAS } \\
\text { Conforto ambiental } \\
\text { Urbanismo e meio ambiente } \\
\text { Paisagismo } \\
\text { DISCIPLINA OPTATIVA } \\
\text { Sustentabilidade na arquitetura e } \\
\text { urbanismo }\end{array}$ \\
\hline \multirow[t]{2}{*}{ UEMS } & $\begin{array}{l}\text { Geografia } \\
\text { (Campo Grande, } \\
\text { Glória de Dourados e } \\
\text { Jardim) }\end{array}$ & $\begin{array}{l}\text { ( ) Sim } \\
\text { (x) Não }\end{array}$ & $\begin{array}{l}\text { DISCIPLINAS OBRIGATÓRIAS } \\
\text { Geografia e Meio Ambiente } \\
\text { Fundamentos de Hidrologia } \\
\text { Aspectos Geoambientais de Mato Grosso } \\
\text { do Sul } \\
\text { Fundamentos de Climatologia }\end{array}$ \\
\hline & $\begin{array}{l}\text { Turismo } \\
\text { (Campo Grande, } \\
\text { Jardim e Dourados) }\end{array}$ & $\begin{array}{l}\text { ( ) Sim } \\
\text { (x) Não }\end{array}$ & $\begin{array}{l}\text { DISCIPLINAS OBRIGATÓRIAS } \\
\text { Ciências Ambientais } \\
\text { Ética e Turismo } \\
\text { Percepção Ambiental } \\
\text { Planejamento e Organização do Turismo } \\
\text { em Ambientes Naturais } \\
\text { Gestão Ambiental } \\
\text { Técnicas Avançadas de Turismo em } \\
\text { Ambientes Naturais } \\
\text { Ecoturismo } \\
\text { Meio Ambiente e Globalização } \\
\text { Turismo Urbano e Rural }\end{array}$ \\
\hline
\end{tabular}


...continuação.

\begin{tabular}{|c|c|c|c|}
\hline IES & CURSO & $\begin{array}{l}\text { CONTEMPLA A } \\
\text { EA NA MATRIZ } \\
\text { CURRICULAR** }^{\star 2}\end{array}$ & DISCIPLINAS CORRELATAS \\
\hline \multirow[t]{2}{*}{$\begin{array}{c}\text { UCDB } \\
\text { (Campo Grande) }\end{array}$} & Geografia & $\begin{array}{l}\text { ( ) Sim } \\
\text { ( x ) Não }\end{array}$ & $\begin{array}{l}\text { DISCIPLINAS OBRIGATÓRIAS } \\
\text { Biodiversidade } \\
\text { Climatologia } \\
\text { Geociências e Recursos Nacionais } \\
\text { Geografia Rural } \\
\text { Humanidades: sociedade e natureza }\end{array}$ \\
\hline & Arquitetura* $^{*}$ & $\begin{array}{l}\text { ( ) Sim } \\
(x) \text { Não }\end{array}$ & $\begin{array}{l}\text { DISCIPLINAS OBRIGATÓRIAS } \\
\text { Conforto ambiental } \\
\text { Estudos Ambientais }\end{array}$ \\
\hline $\begin{array}{l}\text { UNIDERP/ } \\
\text { ANHANGUERA } \\
\text { (Campo Grande) }\end{array}$ & Arquitetura* $^{*}$ & $\begin{array}{l}\text { ( })^{\text {Sim }} \\
(x) \text { Não }\end{array}$ & $\begin{array}{l}\text { DISCIPLINAS OBRIGATÓRIAS } \\
\text { Estudos Sociais, Econômicos e } \\
\text { Ambientais } \\
\text { TDA - Responsabilidade Social e Meio } \\
\text { Ambiente } \\
\text { Conforto Ambiental } \\
\text { Projeto de Arquitetura, Urbanismo e } \\
\text { Paisagismo } \\
\text { Paisagismo }\end{array}$ \\
\hline $\begin{array}{l}\text { UNIGRAN } \\
\text { (Dourados) }\end{array}$ & Arquitetura* $^{*}$ & $\begin{array}{l}\text { ( ) Sim } \\
\text { ( } x) \text { Não }\end{array}$ & $\begin{array}{l}\text { DISCIPLINAS OBRIGATÓRIAS } \\
\text { Conforto ambiental } \\
\text { Estudos Sociais e Ambientais } \\
\text { Paisagismo } \\
\text { Conforto Ambiental }\end{array}$ \\
\hline \multirow[t]{2}{*}{$\begin{array}{c}\text { AEMS } \\
\text { (Três Lagoas) }\end{array}$} & Arquitetura* $^{*}$ & $\begin{array}{l}\text { ( ) Sim } \\
(x) \text { Não }\end{array}$ & $\begin{array}{l}\text { DISCIPLINAS OBRIGATÓRIAS } \\
\text { Ciências Ambientais } \\
\text { Paisagismo }\end{array}$ \\
\hline & Turismo & $\begin{array}{l}\text { ( ) Sim } \\
(x) \text { Não }\end{array}$ & $\begin{array}{l}\text { DISCIPLINAS OBRIGATÓRIAS } \\
\text { Planejamento e Organização do Turismo } \\
\text { Turismo e Meio Ambiente }\end{array}$ \\
\hline $\begin{array}{c}\text { UFGD } \\
\text { (Dourados) }\end{array}$ & Geografia & $\begin{array}{l}\text { ( }) \operatorname{Sim} \\
(x) \text { Não }\end{array}$ & $\begin{array}{l}\text { DISCIPLINAS OBRIGATÓRIAS } \\
\text { Sociedade, meio ambiente } \\
\text { sustentabilidade } \\
\text { Climatologia geográfica } \\
\text { Fundamentos de biogeografia } \\
\text { Geografia e natureza: concepções e } \\
\text { abordagens } \\
\text { Hidrografia } \\
\text { Planejamento ambiental } \\
\text { Agricultura, desenvolvimento e ambiente } \\
\text { Climatologia urbana } \\
\text { Ensino de geografia e meio ambiente } \\
\text { Geografia e estudos ambientais } \\
\text { Técnicas de análise ambiental }\end{array}$ \\
\hline
\end{tabular}

Fonte: INEP - Instituto Nacional de Estudos e Pesquisas Educacionais Anísio Teixeira (2014).

${ }^{*}$ ABEA - Associação Brasileira de Ensino em Arquitetura e Urbanismo (2014).

${ }^{* *}$ Pesquisa realizada nos sites oficiais das IES de MS. 
O Quadro 1 demonstra claramente o universo abordado sobre o contexto de implantação da disciplina de Educação Ambiental no ensino superior dos cursos de Geografia, Arquitetura \& Urbanismo e de Turismo no estado de Mato Grosso do Sul, ou seja, dos 21 cursos superiores investigados, apenas 05 cursos, ou seja, $23 \%$ oferecem a referida disciplina.

Nessa realidade, as políticas de Educação Ambiental, conforme a Lei no 9.795, de 27 de abril de 1999 e Decreto № 4.281 de 25 de junho de 2002, indicativo legal de avaliação vinculado no instrumento de avaliação in loco de autorização e reconhecimento dos cursos de graduação do sistema federal de ensino (com exceção de algumas IES estaduais, como no caso da UEMS) revelam o descumprimento desse item legal.

$O$ que se percebe na investigação com IES do Estado considerando aquelas que ainda não fomentam a disciplina de Educação Ambiental é que esse conteúdo é tratado isoladamente como atividades de extensão, ou seja, com a realização de eventos para discutir essa inserção no contexto universitário, alguns revelam ainda nos sites institucionais a realização de atividades denominadas "Semana do Meio Ambiente" fomentado no mês de junho, considerando o dia 5, alusivo ao Dia Mundial do Meio Ambiente que começou a ser comemorado em 1972, em Estocolmo com a primeira Conferência das Nações Unidas sobre o ambiente humano com o objetivo de promover atividades de proteção e preservação do meio ambiente e alertar o público mundial e governos de cada país para os perigos de negligenciarmos a tarefa de cuidar do meio ambiente.

\section{Considerações finais}

Como se percebeu até o momento nos referenciais epistemológicos e na pesquisa de campo, a Educação Ambiental procura garantir em sua gênese a manutenção da cidadania dos indivíduos. A disseminação dos valores atribuídos ao tema devem ser fomentados em sala de aula por meio dos professores que ao aplicar os conteúdos teórico-práticos, como estudos dirigidos, seminários, rodas de conversas, jogos, entre outras práticas, estimulando o raciocínio e reflexão de se pensar o ambiente como recurso esgotável.

O que pode ser evidenciado na coleta de informações nos sites das IES do Estado é a fragilidade na aplicação de uma disciplina específica de Educação Ambiental nos cursos superiores pesquisados, sobretudo, no contexto de produção e reprodução da natureza em função do desenvolvimento socioeconômico.

Relacionando a formação do Geógrafo, profissão reconhecida sobre o Decreto n. 23.569 de 11 de dezembro de 1933 cuja imputação profissional está deliberada no Artigo 35, mesmo sendo um profissional apto para compreender as dinâmicas e os conflitos existentes a partir da relação homem-natureza, compreendendo, estudando, e apontando soluções para problemas socioambientais em escalas local, regional, nacional ou mesmo internacional Revbea, São Paulo, V.11, № 2: 164-177, 2016. 
apesar de se destacar comparados as demais formações, percebe-se mesmo assim uma lacuna na formação quando comparada a matriz curricular do curso superior ao que preconiza a Lei 9.795 que dispõe sobre a Educação Ambiental (EA), que configura a Política Nacional de Educação Ambiental (PNEA) além da DCN publicada sobre esse assunto.

Da mesma forma, a formação do Arquiteto Urbanista, profissão reconhecida da mesma forma que o Geógrafo, sobre o Decreto n. 23.569 de 11 de dezembro de 1933 cuja atribuição profissionais está definida no Artigo 30, que muitas vezes ao apoiar-se ao marketing dos produtos destinados à arquitetura nos modelos de arquitetura sustentável, arquitetura verde, arquitetura ecologicamente correta, bio-arquitetura, entre outras, fica a preocupação se esse profissional formado no Estado, detêm as competências e habilidades para executar com responsabilidade essa a inserção ambiental nos projetos empreendidos.

Não diferente entre os demais, a formação do Turismólogo, profissão somente reconhecida com a Lei oㅜ 12.591, de 18 de janeiro de 2012, conforme Art. $2^{\circ}$ consideram-se atividades do Turismólogo: "Il - coordenar e orientar trabalhos de seleção e classificação de locais e áreas de interesse turístico, visando ao adequado aproveitamento dos recursos naturais e culturais, de acordo com sua natureza geográfica, histórica, artística e cultural (...)", ou seja, para atender o que determina as obrigações desse profissional, a questão ambiental está incluída, dessa forma, é preocupante a forma como está sendo pensada essa formação considerando o perfil do egresso dos cursos superiores oferecidos em Mato Grosso do Sul.

Dessa forma, retomando a problemática inicial da pesquisa, ou seja, de que modo à Educação Ambiental pode estar inserida às disciplinas dos cursos de Geografia, de Arquitetura \& Urbanismo e de Turismo de modo transversal, contínuo e permanente? Uma das respostas possíveis seria o que o próprio inventário apontou, começa-se pela valorização e implantação urgente da disciplina de Educação Ambiental nos currículos acadêmicos. Após esse trabalho, desenvolvidos pelos órgãos colegiados de cursos, é preciso pensar na transversalidade de modo a garantir a inserção desse tema nos ementários das disciplinas disponíveis. Ainda assim, a continuidade e permanência desse conteúdo poderá ser garantido por meio da discussão coletivamente dos planos de ensino no início de cada semestre além da implantação de projetos integradores de ensino, pesquisa e extensão, onde os professores de cada semestre, conforme suas afinidades, lançam mão de atividades sistemáticas de aprendizagem.

A universidade, portanto, é o espaço de produção do conhecimento, onde essa ideia ecológica pode ser concretizada e repassada de cidadão para cidadão, com o aperfeiçoamento e aprofundamento do estudo, independente da área escolhida pelo estudante para formação superior. $O$ fator principal que poderia auxiliar nessa transformação é a transversalidade que visa uma função de transmitir informações de forma interdisciplinar e transdisciplinar sobre o ambiente.

revista brasileira educação ambiental 


\section{Referências}

ABEA. Associação Brasileira de Ensino de Arquitetura e Urbanismo. Cursos de Arquitetura e Urbanismo. Disponível:< http://www.abea.org.br/?page id=11> Acesso em: 13 Ago. 2014.

BRASIL. Ministério do Meio Ambiente. Conferência das Nações Unidas sobre o Meio Ambiente Humano, reunida em Estocolmo de 5 a 16 de junho de 1972. Disponível: $\quad$ www.mma.gov.br/estruturas/agenda21/ arquivos/estocolmo.doc>. Acesso em 06 Ago.2014.

BRASIL. Conselho Nacional de Educação. Câmara de Educação Superior. Resolução CNE/CES 14, de 13 de março de 2002. Estabelece as Diretrizes Curriculares para os cursos de Geografia. Publicado no D.O.U em 09 de abril de 2002. Seção I, p.33. Disponível: $<$ http://portal.mec.gov.br/cne/arquivos/pdf/CES142002.pdf>. Acesso em 06 Ago. 2014.

BRASIL. Conselho Nacional de Educação. Câmara de Educação Superior. Resolução n13, de 24 de novembro de 2006. Institui as Diretrizes Curriculares do curso de Graduação em Turismo. Publicado no D.O.U em 28 de novembro de 2006. Seção l, p.96. Disponível: <http://portal.mec.gov.br/cne/arquivos/pdf/rces13_06.pdf>. Acesso em 06 Ago. 2014.

BRASIL. Constituição da Republica Federativa 1988. $<$ http://www.jusbrasil.com.br/topicos/10647013/artigo-218-da-constituicao-federalde-1988>. Acesso em: 11 Ago.2014.

BRASIL. Ministério da Educação. CAPES (Coordenação de Aperfeiçoamento de Pessoal de Nível Superior). Tabelas de área de conhecimento. Disponível em http://www.capes.gov.br/avaliacao/instrumentos-de-apoio/tabela-de-areas-doconhecimento-avaliacao. Acesso em 13 Ago.2014.

BRASIL. Ministério da Educação. Diretrizes Curriculares Nacionais Gerais da Educação Básica. Secretaria de Educação Básica. Diretoria de Currículos e Educação Integral.Brasília: MEC, SEB, DICEI, 2013.

BRASIL. Ministério da Educação. Parâmetros Curriculares Nacionais do Curso de Arquitetura e Urbanismo. Disponível em: http://portal.mec.gov.br/index.php?option=com content\&id=12991:diretrizescurriculares-cursos-de-graduacao. Acesso em 06.Ago.2014.

BRASIL. Presidência da República. Decreto № 12.591 de 11 de janeiro de 2012: Reconhece a profissão de Turismólogo. Publicado no D.O.U. em 19/01/2012. Disponível: < http://www.planalto.gov.br/ccivil_03/_ato20112014/2012/lei/l12591.htm >. Acesso em 06 Ago. 2014.

BRASIL. Presidência da República. Decreto № 23.569 de 11 de dezembro de 1933: Regula o exercício das profissões de engenheiro, de arquiteto e de agrimensor. Publicado no CLBR. em 31/12/1933. Disponível: < http://www.planalto.gov.br/ccivil_03/decreto/1930-1949/D23569.htm>. Acesso em 06 Ago. 2014. 
BRASIL. Presidência da República. Decreto № 4.281 de 25 de junho de 2002: Regulamenta a Lei o 9.795, de 27 de abril de 1999, que institui a Política Nacional de Educação Ambiental. Publicado no D.O.U. em 26/06/2002. Disponível: < http://www.planalto.gov.br/ccivil_03/decreto/2002/D4281.htm>. Acesso em 06 Ago. 2014.

BRASIL. Presidência da República. Lei no. 9394 de 20 de dezembro de 1996: (LDB) Lei de Diretrizes e Bases. Publicado no D.O.U. em 20/12/1996.Disponível: http://www.planalto.gov.br/ccivil 03/leis//9394.htm. Acesso em 06 Ago.2014.

BRASIL. Presidência da República. Lei no. 9795 de 27 de abril de 1999: Política Nacional de Educação Ambiental. Publicado no D.O.U. em 28/04/1999. Disponível: <http://www.planalto.gov.br/ccivil_03/Leis/L9795.htm>. Acesso em 06 Ago. 2014.

BRASIL. Secretaria de Educação Fundamental. Ministério da Educação e Cultura. Parâmetros Curriculares Nacionais: Geografia. Brasília. MEC/SEF, 1998. Disponível: < http://portal.mec.gov.br/seb/arquivos/pdf/geografia.pdf>. Acesso em 11 de Ago.2014.

BRÜGER, P. Educação ou adestramento ambiental? Florianópolis: Letras Contemporâneas, 1999.

CONFEA. Conselho Federal de Engenharia, Arquitetura e Agronomia. Lei 6.664 de 26 de junho de 1979: Disciplina a profissão de Geógrafo e dá outras providências. Publicado no D.O.U em 27 JUN 1979 - Seção I - Pág. 9.017. Disponível: < http://normativos.confea.org.br/downloads/6664-79.pdf>. Acesso em 11 Ago. 2014.

CONFERÊNCIA de Tbilisi na Geórgia. Disponível em: $<$ http://www.portaleducacao.com.br/biologia/artigos/27425/conferencia-de-tbilisi-

1977>. Acesso em 11 Ago. 2014.

CRISToFOLETTI, A. Impactos no meio ambiente ocasionado pela urbanização tropical. In: SANTOS, M.; SOUZA, M.A.; SCARLATO, F.C.; ARROYO, M. Natureza e Sociedade hoje: Uma Leitura Geográfica. 4 ed. São Paulo: Hucitec, 2005.

GARCIA, L.A.M. Temas Transversais como Eixo Unificador. Disponível: <http://www.educacaopublica.ri.gov.br>. Acesso em: 27. Jul. 2014.

PILON, A.F. Ocupação Existencial do Mundo: Uma Proposta Ecossistêmica. In. PHILIPPI, Arlindo Jr.; PELICIONI, Maria Cecília Focesi. Educação Ambiental e Sustentabilidade. Barueri: USP,2005.

SOBRAL, H.R.; SILVA, C.C.A. Balanço sobre a situação do meio ambiente na metrópole de São Paulo. In. PHILIPPI Jr, A..; PELICIONI, M.C.F. Educação Ambiental e Sustentabilidade. Barueri: USP,2005.

ZUQUIM, F.A.; FONSECA, A.R.; CORGOZINHO. B.M.S. Educação Ambiental e cidadania. Revista Educação Ambiental em Ação, n.41. 2012. Disponível: <http://www.revistaea.org/artigo.php?idartigo=1317>. Acesso em: 27 Jul. 2014. 